\title{
DRIVING FACTORS OF SUSTAINABLE TRANSPORTATION: SATISFACTION WITH MODE CHOICES AND MOBILITY CHALLENGES IN OXFORDSHIRE AND HAMBURG
}

\author{
KIMBERLY TATUM ${ }^{1}$, KATIE. PARNELL ${ }^{2}$, TUBA INAL CEKIC ${ }^{3} \&$ JOERG KNIELING $^{4}$ \\ ${ }^{1}$ Hafencity University Department of Planning and Regional Development, Germany \\ ${ }^{2}$ Oxfordshire County Council Innovation Hub, UK \\ ${ }^{3}$ Humboldt University-Berlin and visiting scholar at Hafencity University, Germany \\ ${ }^{4}$ Hafencity University Chair of Planning and Regional Development, Germany
}

\begin{abstract}
Recent decades have seen a shift towards more sustainable transport and support of more balanced development of all modes of transport by many governments, with scholarly articles contributing to the discourse. However, users' attitudes and satisfaction with existing modes of transport determine ultimate acceptance of new transport opportunities. Inclusion of the public is also essential to make a change towards new and more sustainable mobility choices. Accordingly, travel satisfaction as a source of travel mode choice is a significant aspect in the analysis of urban mobility. Different travellers with varying mode choices have different needs and priorities, influencing appreciation of and satisfaction with various aspects of travel.

This paper investigates key factors influencing individual travel behaviours for different travel modes by examining the interactions of mode choice and traveller satisfaction with mobility challenges. Primary data were collected through online surveys conducted as a part of the EU-Horizon 2020-funded Cities-4-People project. Quantitative data were collected to analyse the socio-demographic characteristics of citizens moving daily in the city, their routes, mobility challenges and satisfaction with travelling. This paper presents the findings of the survey conducted in Hamburg-Altona (Germany) and Oxfordshire (UK).

Survey results confirm previous findings and contribute additional evidence suggesting that the main sources of satisfaction from sustainable transportation modes appear to be service quality and infrastructure. Deeper consideration of satisfaction by mode usage allows for some pronounced differences between user types to be analysed.
\end{abstract}

Keywords: mobility challenges, sustainable mobility, travel behaviour, travel mode choice

\section{INTRODUCTION}

Along with increasing public and political emphasis on environmental and sustainability issues, during the last 20 years, many local and national governments have joined in a shift towards sustainable transport modes and a more balanced approach to planning for all transit modes. Yet, as cities set ambitious goals for future mode splits (in Hamburg, for example, to reach $25 \%$ bike mode share by the 2020s [1]), they rely on local citizens to make the switch with them. User attitudes and their satisfaction with existing transport modes determine acceptance of new transport opportunities. Travel mode choice and travel satisfaction as functions of travel behaviour are significant aspects for urban mobility analysis [2, 3]. Given different travellers using different modes have differing needs and priorities influencing appreciation of, and satisfaction with, various travel aspects, current mode choice decisions and current satisfaction can inform potential uptake of alternative or new modes $[2,4]$.

This study aims to investigate key challenges and factors influencing mode choice by identifying mobility challenges correlated to user preferences. We draw on the results of a survey conducted in the five pilot areas of the Cities-4-People project (Oxfordshire, Hamburg-Altona, 
Budapest, Trikala and Üsküdar in Istanbul) during autumn 2017, to identify and describe local mobility challenges. Citizens shared information about mode choice for different travel purposes, satisfaction with modes and general demographic characteristics. The following analysis investigates the impacts of specific mobility challenges on different types of travel in Altona and Oxfordshire. It informs on existing and potential obstacles to uptake of the cities' preferred modes.

The following section provides a literature review concerning the challenges of sustainable mobility options and travel mode choice, which is influenced by travel satisfaction. Section 3 presents the data collection method and a description of the sample. Section 4 describes and synthesises findings of the analysis. Finally, this paper concludes by discussing key findings and implications for Altona-Hamburg and Oxfordshire.

\section{MOBILITY CHALLENGES DETERMINE THE TRAVEL MODE CHOICE AND USER SATISFACTION}

The forms of mobility and mobility challenges present in urban environments differ from those in rural, suburban or peri-urban locations; even within an urban setting, challenges will vary between locations, depending on infrastructure, layout, traffic levels, etc. Findings of the surveys, interviews and workshops conducted for the Cities-4-People project and outcomes from previous work undertaken by Oxfordshire County Council show that some of the most common mobility challenges encountered include the following: lack of direct connectivity to locations of interest (e.g. by public transit); poor safety conditions (whether perceived or real); lack of suitable infrastructure or provision of public transport (PT); high traffic volumes, leading to additional challenges such as congestion, slow journeys, poor air quality and poor reliability. Sometimes, the challenges faced are exacerbated or even created by lack of knowledge of options or incorrect assumptions about the options - perception of the challenge becomes the challenge in some instances.

As such, in order to successfully transition to sustainable modes of transportation, it is necessary to fully understand requirements for an area and its citizens, to get to know the area in detail, and see what the needs and patterns of users are. The inclusion of the public in transportation planning and policy furthers this process by generating more detailed information about needs and challenges faced. According to Kandt et al. [5], if policy interventions are 'designed and targeted in accordance with group-specific needs and preferences and respond to local conditions of mobility culture', the potential for uptake is greater.

Existing studies and literature on user satisfaction with transport modes show that challenges faced by travellers affect their satisfaction level with the journey. For example, Cantwell et al.'s [6] study into PT commuting satisfaction in Dublin, Ireland, showed that Dublin PT users experienced greater satisfaction with higher reliability and lower crowding; conversely, satisfaction levels decreased as reliability reduced and crowding went up. Similarly, Olsson et al. [7] argue that a favourable customer experience is 'crucial for the success of a [transport] company's offering', but experience in transport is multidimensional, being affected both cognitively and affectively (i.e. logically and emotionally).

In the past, user satisfaction was equated with simplified utility factors, e.g. speed of journey. More recent research shows how other aspects of a journey can also affect satisfaction. In a 2010 survey from Sweden, Ettema et al. [8] demonstrated a significant positive impact on satisfaction from personal interactions between passengers, whereas either relaxation or entertainment-based activities actually had a negative impact on satisfaction. The authors 
posit this may be due to the possibility that such activities might have been unsuccessful attempts to alleviate boredom. In addition, mindset was also found to be an important determinant of the impact of different activities on satisfaction - activities undertaken during the journey home from work were more successful in increasing satisfaction than those undertaken on the journey into work. This research suggests the inadequacy of utility as a simple measure and demonstrates the need for more detailed investigation of user satisfaction.

Abenoza et al. [9] have also explored how characteristics of travellers influence satisfaction with their transport choices. Different types of traveller (inactive travellers, long-distance commuters, urban motorist commuters, rural motorist commuters and students) show clear similarities and differences, allowing some key determinants to be drawn from the research. Features found to be important to all traveller types were customer interface, operation, network and trip time. Frequent PT users were found, on balance, to be more satisfied in general, whilst rural motorist commuters were considerably more dissatisfied with transit service operation attributes.

User satisfaction itself is also nuanced - Singleton [10], for example, has shown that a user may feel enjoyment with a certain mode while also being concerned about their safety whilst using it. Both cyclists and walkers were found to have higher satisfaction levels with their mode than users of other modes; however, when looking in detail, active travellers scored higher on levels of distress and fear and felt less secure than users of other modes [11]. Insights such as this could allow planners to consider interventions, which are more likely to improve uptake of sustainable travel.

The research shows that user satisfaction and challenges faced when using different mobility forms impact people's choice of travel, though there is a complex relationship between travellers' individual commitment to a particular mode and whether they see this as voluntary or involuntary. User captivity within a given mode is usually fairly specifically defined within the literature, e.g. Krizek and El-Geneidy [2], who use the definition from the American Public Transportation Authority that captive public transit users are those "who do not have a private vehicle available or cannot drive (for any reason) and who must use transit to make a desired trip'; however, it seems to be more complex than this in reality, considering fluctuating fuel prices, transit times and so on, which may lead users to feel captive to a given mode for other reasons. In addition, people have preconceptions of modes of transport, which may lead them to believe that there are challenges that do not exist or are greater than in reality.

Habit is also a significant factor in travel behaviour, which should not be underestimated. Indeed, Middelkoop et al. [4] looked into the heuristics affecting tourists' choice of mode and found a significant number of factors which influence travel decisions, including ownership of a vehicle (which speaks to both access and habitual use). Further to this, previous decisions affect current and future decisions, so if prior trips have been undertaken by a particular mode, the likelihood of future trips consisting of the use of the same mode as previously chosen becomes higher, particularly where the prior trip was of greater importance than the current/future trip. Given the complexity and number of factors involved in travel mode decision, our paper focuses on satisfaction levels with different aspects of various modes of transport, with some references to challenges, where this is inferred from satisfaction. Further factors affecting mode decision, such as habit, preconception, demographic factors and access to/captivity within the mode in question, are outside the scope of this analysis. 


\section{METHODOLOGY AND THE DESCRIPTIVE CHARACTERISTICS OF TWO CITIES}

This paper presents results from a mobility survey performed as part of Cities-4-People (C4P), a project funded by Horizon 2020 European Union Funding for Research and Innovation. $\mathrm{C} 4 \mathrm{P}$ is a three-year project that aims to implement pilot programs in five urban areas. In each city, citizens, city authorities and innovation experts work together as 'mobility communities' to define transport and mobility challenges and priorities, co-design solutions and put these concepts to the test. The survey results analysed here for Hamburg-Altona and Oxfordshire were gathered in the initial phase of defining transport and mobility challenges.

Altona is one of largest districts in the City of Hamburg, making up approximately $14 \%$ of Hamburg's population. The District is densely populated in the centre around Altona Main Station but extends to Hamburg's western border, with progressively more suburban character. The station serves many commuters bound for other parts of the city and integrates three traffic systems: suburban train, long distance and regional trains and (local) buses; significantly, it is not connected to Hamburg's local underground network. Furthermore, Altona is a shopping location, drawing many people from surrounding areas. The older urban infrastructure of narrow, often cobblestoned streets is frequently overwhelmed by transportation demands. In general, the mobility context in Altona is complex and fraught with conflicts - mirroring greater Hamburg, where discussions of transportation are currently a hot-button issue.

As of 2017, Oxford is the 12th fastest-growing and one of the most ethnically diverse UK cities. According to the Index of Multiple Deprivation, some neighbourhoods demonstrate significant inequality in comparison to the rest of Oxford. These areas of economic and social deprivation have led to issues such as persistent poverty and health inequalities. The major employment attractors located in the periphery of the city have led to high volumes of car trips and exacerbated urban mobility challenges like congestion at peak hours. Compared to other towns and cities outside London, Oxford is generally well served by high-quality PT, with a 'turn up and go' level of service on radial routes into the city centre, but with poor or completely lacking services between localities around the periphery of the city. Oxford is a historic city, and, like other cities with a dense built environment and narrow streets, delivering holistic and connected mobility is extremely challenging for transport authorities.

\subsection{Data collection and the survey}

Quantitative data were collected to analyse socio-demographic characteristics of citizens that move daily in the city, their routes and mobility challenges and their satisfaction with travel deriving from their mode choice. These data were collected through an online survey over a period of one month and composed of four sections: demographics, travel habits and patterns, use of smartphones and satisfaction with aspects of mobility related to different modes. Subsequent data cleaning was performed to obtain a relevant comparable dataset, for example, adjustments to standardise education level across German and British contexts. The size of the dataset and the non-randomised recruitment meant it was not possible to determine exactly how socio-demographic characteristics and country-specific cultural differences affect satisfaction with the transport options. Detailed analysis findings are focused on how different urban settings influence travel mode choice.

Data management and analysis were performed using SPSS 20.1 for factor analysis, Student's $T$-test and correspondence analysis, to explain elements conditioning travel mode choice. Factor analysis was used as a means of statistically filtering the data to produce the most representative subset of variables from satisfaction questions. Factor analysis examines 
the inter-correlations that exist between a large number of items and in doing so, reduces the items into dimensions, known as factors, which contain correlated variables and are typically quite similar in terms of content or meaning. The individual qualities of transportation infrastructure or experience, put together in interrelated groups, shows the general mobility challenges facing respondents from each area. Principal component analysis was used to determine the factor and a varimax rotation was performed on the data.

Following the description of the factors, $T$-tests were performed on each resulting factor to determine that factor's significance for different mode user groups, comparing public transitonly commuters to active-only and public transit-only to private motorised-only commuters. Finally, to clarify the relation between the significant challenges and the mode use, we performed correspondence tests to assess the relationship of mode use for work/study trips.

\subsection{Sample descriptives/trip characteristics}

After the process of data cleaning, 861 Hamburg and 244 Oxfordshire questionnaires were taken into account. Hamburg results show a more balanced distribution of gender than Oxfordshire, but also a greater number of participants preferring not to state their gender. The highest proportion of participants is aged between 35 and 64 in both cities $(71.3 \%$ and $73.5 \%$, respectively), and the sample is overrepresented by local middle-income residents with higher education, likely due to sampling and promotion methods. Still, the majority of respondents can access the nearest PT on foot in less than $10 \mathrm{~min}(93 \%$ in Altona and $78 \%$ in Oxfordshire). A majority of respondents own cars and bikes in both cities.

The transport mode choice of respondents (Table 1) reveals that those in Altona use bicycle or PT very regularly for work and education or social and leisure activities. These results

Table 1: Mode choice.

\begin{tabular}{|c|c|c|c|c|c|c|c|c|c|c|c|c|}
\hline \multirow{3}{*}{ Mode choice } & \multicolumn{6}{|c|}{ Hamburg-Altona } & \multicolumn{6}{|c|}{ Oxfordshire } \\
\hline & \multicolumn{2}{|c|}{$\begin{array}{c}\text { Work \& } \\
\text { study }\end{array}$} & \multicolumn{2}{|c|}{$\begin{array}{c}\text { Social- } \\
\text { leisure }\end{array}$} & \multicolumn{2}{|c|}{$\begin{array}{c}\text { Household } \\
\text { tasks }\end{array}$} & \multicolumn{2}{|c|}{$\begin{array}{c}\text { Work \& } \\
\text { study }\end{array}$} & \multicolumn{2}{|c|}{$\begin{array}{l}\text { Social- } \\
\text { leisure }\end{array}$} & \multicolumn{2}{|c|}{$\begin{array}{c}\text { Household } \\
\text { tasks }\end{array}$} \\
\hline & $N$ & $\%$ & $N$ & $\%$ & $N$ & $\%$ & $N$ & $\%$ & $N$ & $\%$ & $N$ & $\%$ \\
\hline Bicycle & 485 & 23.8 & 577 & 21.7 & 447 & 29.2 & 50 & 16.3 & 41 & 12.0 & 31 & 11.2 \\
\hline Train-PT* & & & & & & & 19 & 6.2 & 7 & 2.1 & - & - \\
\hline Bus-PT* & 382 & 18.1 & $4 / 4$ & 17.8 & 101 & 0.6 & 85 & 27.7 & 88 & 25.8 & 17 & 6.1 \\
\hline On foot & 190 & 9.3 & 330 & 12.4 & 502 & 32.8 & 51 & 16.6 & 76 & 22.3 & 74 & 26.7 \\
\hline Pedelec/E bike & 6 & 0.3 & 9 & 0.3 & 6 & 0.4 & - & - & - & - & - & - \\
\hline Private car & 163 & 8.0 & 175 & 6.6 & 237 & 15.5 & 97 & 31.6 & 110 & 32.3 & 146 & 52.7 \\
\hline Car share & 11 & 0.5 & 68 & 2.6 & 16 & 1.0 & 2 & 0.7 & 15 & 4.4 & 3 & 1.1 \\
\hline Bike share & 28 & 1.4 & 74 & 2.8 & 13 & 0.9 & - & - & - & - & - & - \\
\hline Motorcycle/roller & 12 & 0.6 & 11 & 0.4 & 5 & 0.3 & - & - & - & - & - & - \\
\hline
\end{tabular}

Pedelec: a bicycle where the rider's pedalling is assisted by a small electric motor.

PT: public transportation.

*In Hamburg, all public transit options were offered as a combined option; in Oxfordshire, bus and train were separated. 
match with the most recent national travel survey [12]. When it comes to household tasks, PT use drops considerably: the majority use Active Travel (AT). This result can be related to unequal distribution of surveys throughout the city in terms of residential location, where $97 \%$ of the respondents report living in the city centre and are well served by many nearby markets, pharmacies, etc. Respondents from Altona prefer AT: less than $10 \%$ of the participants choose Private Motorized (PM) to travel between home and work/travel and social and leisure activities (8\% and 6.6\%, respectively), and PM is mostly preferred for household tasks with $15.5 \%$ choosing this option. Car ownership in Altona was measured at about $56 \%$ of households in Altona in the national survey (MID 2018) and about 52\% of respondents in our survey, so this does not account for a major difference. Lower reported PM use in our survey for these purposes is also likely due to the central living location of most respondents.

PM use is also highest in Oxfordshire $(52.7 \%)$ when it comes to household tasks, which could be related to the balanced distribution of residential location across centre, suburb and rural contexts. But overall, unlike Altona, PM is the most desired mode also in terms of work, study, social and leisure trips (31.6\% and 32.3\%, respectively). The observed level of bicycle use is consistent with figures for Oxford from the 2011 Census [13], which reported $17 \%$ of residents cycled to work. However, outside the city centre, this figure is much lower (e.g. Headington $10 \%$ ). These figures compare to a national average of only $2.8 \%$ of people cycling to work in the same year.

\section{FINDINGS}

The factor analysis highlighted the satisfaction indicators with the highest influence. Twenty indicators were used and three items were eliminated, as they did not contribute to a simple factor structure and failed to meet a minimum criterion of a primary factor loading of 0.5 or above. The satisfaction indicators were thus grouped into six and five factors summarising the mobility challenges for Hamburg-Altona and Oxfordshire, respectively. The six selected factors in Altona explain $67 \%$ of the total variance. The percentage of variability explained by factor 1, summarised as 'traffic-related impacts', is $25.8 \%$, including noise, speed of vehicle traffic and air quality. Factors in Oxfordshire explain $64.5 \%$ of the total variance and, different than Altona, five factors explain the variability. The percentage of variability explained by the first factor $1(29.3 \%)$ is higher in Oxfordshire. This is summarised as 'ease of public transit usage' and includes frequency of services, distance between nearest stop and house/ work, number of transfers necessary and services are on schedule. For both cities, the first three factors explain almost $50 \%$ of variance.

To determine how the factors impact different traveller types, an independent-samples $T$-test was performed. The factor scores were compared for PT users and active travellers, including foot and bike (AT) and followed by a comparison between PT users and private car users (PM). In these cases, the work or study mode provided was used, to represent daily travel choices, and multimodal responses were kept separate. The mode users therefore represent heavy users of these modes. $T$-tests allow for a comparison of the challenges between different commuter mode users, which demonstrates how certain challenges may be more relevant to daily users of certain modes and may perhaps inform mode selection. The results obtained from $T$-test analysis are presented in Table 2 (for p-values, see Appendix).

According to the results for Altona, satisfaction with traffic-related impacts is significantly different among AT-only, PT-only and PM-only users. Results reveal that active commuters are significantly less satisfied with the motorised traffic-generated impacts when compared to PT commuters, while PT commuters are significantly less satisfied with these impacts than PM users. There is also a significant difference in the satisfaction score for reliability of PT 
Table 2: Summary of $T$-tests for factors between PT and AT and PT and PM Prepared by the authors.

\begin{tabular}{|c|c|c|c|c|}
\hline & $\begin{array}{l}\text { Commute PT only } \\
\text { vs AT only }\end{array}$ & $\begin{array}{l}\text { Satisfaction } \\
\text { of PT }\end{array}$ & $\begin{array}{l}\text { Commute PT only } \\
\text { vs PM only }\end{array}$ & $\begin{array}{l}\text { Satisfaction } \\
\text { of PT }\end{array}$ \\
\hline \multirow[t]{6}{*}{ Altona } & $\begin{array}{l}\text { Traffic-related } \\
\text { impacts }\end{array}$ & Higher*** & $\begin{array}{l}\text { Traffic-related } \\
\text { impacts }\end{array}$ & Lower*** \\
\hline & $\begin{array}{l}\text { Public transit } \\
\text { comfort }\end{array}$ & Lower & Public transit comfort & Higher \\
\hline & $\begin{array}{l}\text { Reliability of public } \\
\text { transit }\end{array}$ & Lower*** & $\begin{array}{l}\text { Reliability of public } \\
\text { transit }\end{array}$ & Lower \\
\hline & $\begin{array}{l}\text { Pedestrian } \\
\text { infrastructure }\end{array}$ & Higher** & $\begin{array}{l}\text { Pedestrian } \\
\text { infrastructure }\end{array}$ & Higher \\
\hline & $\begin{array}{l}\text { Access to transit } \\
\text { and destinations }\end{array}$ & Higher** & $\begin{array}{l}\text { Access to transit and } \\
\text { destinations }\end{array}$ & Higher*** \\
\hline & $\begin{array}{l}\text { Green and public } \\
\text { space }\end{array}$ & Higher & $\begin{array}{l}\text { Green and public } \\
\text { space }\end{array}$ & Lower \\
\hline \multirow[t]{5}{*}{ Oxford-shire } & $\begin{array}{l}\text { Ease of public tran- } \\
\text { sit usage }\end{array}$ & Lower & $\begin{array}{l}\text { Ease of public transit } \\
\text { usage }\end{array}$ & Lower \\
\hline & $\begin{array}{l}\text { Public transit } \\
\text { comfort }\end{array}$ & Lower & Public transit comfort & Lower \\
\hline & $\begin{array}{l}\text { Public space quality } \\
\text { and access }\end{array}$ & Lower & $\begin{array}{l}\text { Public space quality } \\
\text { and access }\end{array}$ & Lower \\
\hline & $\begin{array}{l}\text { Traffic-related } \\
\text { impacts }\end{array}$ & Higher & $\begin{array}{l}\text { Traffic-related } \\
\text { impacts }\end{array}$ & Lower \\
\hline & $\begin{array}{l}\text { Pedestrian } \\
\text { infrastructure }\end{array}$ & Lower** & $\begin{array}{l}\text { Pedestrian } \\
\text { infrastructure }\end{array}$ & Lower** \\
\hline
\end{tabular}

$* * * 99 \%$ or $* * 95 \%$ significance.

for ATs and PT users, with PTs having lower satisfaction. In addition, PM users are much less satisfied with access to transit and destinations than PT users. Results for Oxfordshire reveal fewer significant differences in satisfaction with different challenge factors, though the score for pedestrian infrastructure is significantly lower among PT users than AT users. This outcome in Oxfordshire may be related to the broad geography covered in the survey responses and suggests that challenges experienced by mode users may need to be examined at a more granular level.

The $T$-tests do not provide a complete picture of mode choice. Lower satisfaction on a certain metric may have to do with more experience or captivity with this particular challenge. Krizek and El-Geneidy [2] note that captive users of PT (i.e. those without access to a vehicle or other alternative option) are less affected by reductions in service quality than those choosing to use it over other alternative options, suggesting that they may have a lower satisfaction level without moving modes than counterparts with a choice. It may be that our sample contains a high proportion of captive PT users, explaining this lower satisfaction level. Alternatively, it could be that PT riders are more exposed to problems with vehicle 
scheduling and frequency and therefore are more dissatisfied with reliability, whereas other mode users would not experience these issues. On the other hand, lower satisfaction may be associated with lower use of the mode, e.g. PMs dissatisfied with transit reliability, and therefore with a negative perception, as Abenoza et al. [9] also found in their study. This is an important distinction when considering whether potential mobility solutions will influence mode choice. To further examine to what extent these relationships with mode use and satisfaction exist in Hamburg and Oxfordshire, correspondence analysis was performed for the significant challenge factors, comparing satisfaction with mode use. In this, round multimodal responses were examined closely, as these travellers have shown themselves open to changing commute mode. Results are shown in Fig. 1.
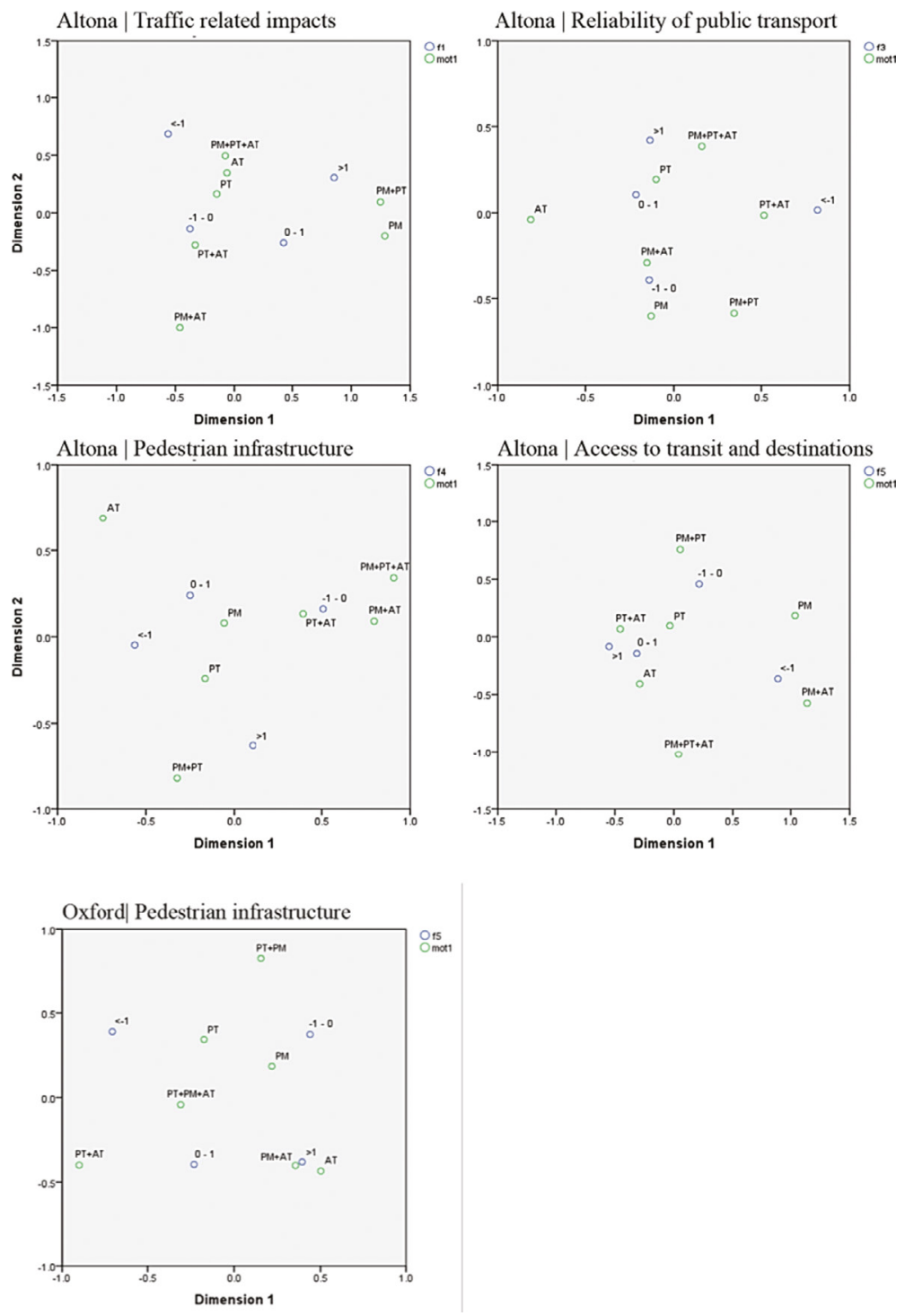

Figure 1: Altona correspondence analysis. 
In Altona, the strongest relationship in the correspondence analysis for traffic-related impacts is with dissatisfaction and AT use, alone or in combination with any other mode. PM-only users and PM+PT users show higher satisfaction. AT-only users can be seen to be more committed, as they persist in the mode use, despite higher dissatisfaction. However, dissatisfaction with traffic impacts (noise, speed and air quality) may be influencing the mode choice of multimodal users who are open to AT use. For reliability of public transit, a negative relationship between AT-only users and high dissatisfaction is shown but also a strong relationship between PT+AT users and high dissatisfaction. Those who are using only AT are more satisfied than those combining PT and AT. This may indicate that AT offers an alternative to PT users who are dissatisfied with transit scheduling, information and frequency in Altona, but also speaks to the difficulties, which arise when combining the modes. The ban on bicycles in Hamburg's PT during rush hours could, for example, contribute to this dissatisfaction. For access to transit and destinations, the correspondence analysis confirms $T$-test results, showing a strong relationship between PM+AT users and high dissatisfaction, between PM+PT users and dissatisfaction and a strong negative relationship between PM-only users and high satisfaction. In this case, the access to public transit (stop distance, changes necessary) seems to be related to users' choice of PM and, in some cases, AT as an alternative mode.

For pedestrian infrastructure in Altona, the correspondence analysis shows a significant negative relationship between AT-only users and high satisfaction. Multimodal users $(\mathrm{PM}+\mathrm{PT}+\mathrm{AT}, \mathrm{PM}+\mathrm{AT}$ and $\mathrm{PT}+\mathrm{AT})$ are also less satisfied with pedestrian infrastructure, although still more satisfied than AT only. This implies that those using the pavements, street crossings, etc., on a day-to-day basis in Altona are less satisfied and that this dissatisfaction may be a contributing factor for multimodal users to turn to other modes for certain routes or purposes. In Oxfordshire, the correspondence analysis of the pedestrian infrastructure factor confirms the $T$-test results, with AT and PM+AT users generally more satisfied and less dissatisfied and PT and PT+PM users less satisfied. This is an interesting result and may indicate that pedestrian infrastructure in Oxfordshire connecting to PT stops may be a significant challenge. However, whilst PT users are generally more dissatisfied, when users are both PT and AT, they are generally more satisfied. This could suggest that use of AT is infrastructure dependent to some degree - i.e. those with access to the better facilities are more likely to use them than those who do not have access. The sample from Oxfordshire covers a wide geographical area, and infrastructure provision varies significantly - being generally better in the more urban areas of the county - possibly explaining the above finding.

\section{DISCUSSION AND CONCLUSION}

Many cities are now trying to encourage significant changes to their mobility patterns. As they strive to reach goals for carbon reduction and overall sustainability, they hope to increase mode shares for active and public transit options and to reduce private vehicle use. Active and public modes are more supported at policy levels due to environmental-friendliness and potential for higher efficiency and use of space of existing transportation infrastructures. Still, there seems to be a primary mindset among policy-makers seeking to promote changes in mode share: infrastructural solutions ('if you build it, they will come'). Included in this could be large-scale expansions to transportation offerings (new bus or train routes) or efforts to increase attractiveness of a mode (free Wi-Fi in trains and buses). But do these measures respond to the challenges citizens face in their everyday travels? Based on a survey of travellers in Hamburg-Altona, Germany and Oxfordshire, England, we consider the interplay of travel satisfaction, socio-economic characteristics and mode preference on mode choice for work or study trips (daily travel). 
- How to create a more complete picture of mode choice in the study areas?

- What relationships exist between mode choice and satisfaction?

Factor analysis was used to identify six central mobility challenges in Altona and five in Oxfordshire. In both focus areas, satisfaction with different transportation factors can be shown to vary greatly according to individual constellations of mode usage. The reported levels of satisfaction from different mode use combinations show the challenges most relevant to those user groups. Comparisons of single and multimodal users, specifically, can inform about decision-making on mode choice.

This analysis shows that before mobility interventions are considered, the goals of the interventions must first be outlined. We recommend consideration of these goals in specific relationship to desired mode switch. New mode split targets to increase sustainable transportation usage must be set with the acknowledgement that travellers must make the choice to switch from or at least reduce the frequency of use of their previous modes. Appropriate measures can then be taken to encourage uptake of more sustainable modes. For example, if the goal is to increase PT and reduce PM use in Altona, our analysis indicates that measures to improve access to transit and destinations would be most appropriate as this is a stronger driver of satisfaction and is more strongly related to local mode choice than attractiveness factors such as comfort. A goal to increase AT use in Altona should be accompanied by measures to improve traffic-related impacts and pedestrian infrastructure and be targeted at multimodal users who are already open to active transit.

In Oxfordshire, PT users seem to be generally dissatisfied, implying they are captive users. Measures to increase PT attractiveness may improve their satisfaction but may not strongly impact a switch to PT by other mode users. If seeking to increase AT in Oxfordshire, an option could be to improve infrastructure in areas currently poorly provided for, though further research to support this finding would be useful to confirm the interpretation of this study's analysis. Also, goals should be reasonable, considering the socio-economic character of the cities, and blanket goals should be avoided. Looking at these characteristics could help inform where and how mobility interventions are best targeted for greatest impact. Detailed investigations of mobility challenges should be performed at the neighbourhood level to provide context for these decisions. Finally, mode preference is significant, speaking to the role of knowledge, education and perception of different modes. Cities hoping to encourage mode switches should consider investing in, or otherwise encouraging, campaigns to advertise or educate about preferred modes.

\section{REFERENCES}

[1] Freie und Hansestadt Hamburg, Radverkehrsstrategie für Hamburg, available at https:// www.hamburg.de/contentblob/129682/9d37bbb142c189e8a3ddad3d4566d896/data/ radverkehrsstrategie-fuer-hamburg.pdf, 2007.

[2] Krizek, L.J. \& El-Geneidy, A., Segmenting preferences and habits of transit users and non-users. Journal of Public Transportation, 12(2), pp. 71-94, 2007.

[3] Beirão, G., \& Cabral, J. S. Understanding attitudes towards public transport and private car: a qualitative study. Transport Policy, 14(6), pp. 478-489, 2007.

[4] Middelkoop, M.V., Borgers, A. \& Timmermans, H., Inducing heuristic principles of tourist choice of travel mode: a rule-based approach. Journal of Travel Research, 42(1), pp.75-83, Aug 2003.

[5] Kandt, J., Rode, P., Hoffmann, C., Graff, A. \& Smith, D., Gauging interventions for sustainable travel: a comparative study of travel attitudes in Berlin and London. Transportation Research Part A: Policy and Practice, 80, pp. 35-48, Aug 2015. 
[6] Cantwell, M., Caulfield, B. \& O’Mahony, M., Examining the factors that impact public transport commuting satisfaction. Journal of Public Transportation, 12(2), pp. 1-21, 2009.

[7] Olsson, L.E., Friman, M., Pareigis, J. \& Edvardsson, B., Measuring service experience: applying the satisfaction with travel scale in public transport. Journal of Retailing and Consumer Services, 19(4), pp. 413-418, May 2012.

[8] Ettema, D., Friman, M., Gärling, T., Olsson, L.E. \& Fujii, S., How in-vehicle activities affect work commuters' satisfaction with public transport. Journal of Transport Geography, 24, pp. 215-222, 2012.

[9] Abenoza, R.F., Cats, O. \& Susilo, Y.O., Travel satisfaction with public transport: determinants, user classes, regional disparities and their evolution. Transportation Research Part A: Policy and Practice, 95, pp. 64-84, Nov 2016.

[10] Singleton, P.A., Walking (and cycling) to well-being: modal and other determinants of subjective well-being during the commute. Travel Behaviour and Society, 2018. DOI: $10.1016 /$ j.tbs.2018.02.005.

[11] Lachapelle, U., \& Noland, R. B. (2012). Does the commute mode affect the frequency of walking behavior? The public transit link. Transport policy, 21, pp. 26-36, 2012.

[12] Bundesministerium für Verkehr und digitale Infrastruktur (2018) Mobilität in Deutschland: Kurzreport Hamburg und Metropolregion, available at https://www. hamburg.de/contentblob/11914848/66802cb6f20f2b2e9d84c3da37054f5f/data/mid2017-\%E2\%80\%93-kurzreport-hamburg-und-metropolregion.pdf.

[13] Census Analysis-2011-Cycling to Work, Oxfordshire, available at https://webarchive. nationalarchives.gov.uk/20160105224307/http://www.ons.gov.uk/ons/rel/census/2011census-analysis/cycling-to-work/2011-census-analysis---cycling-to-work.html. 
APPENDIX

Table 3: Results of $T$-test analysis.

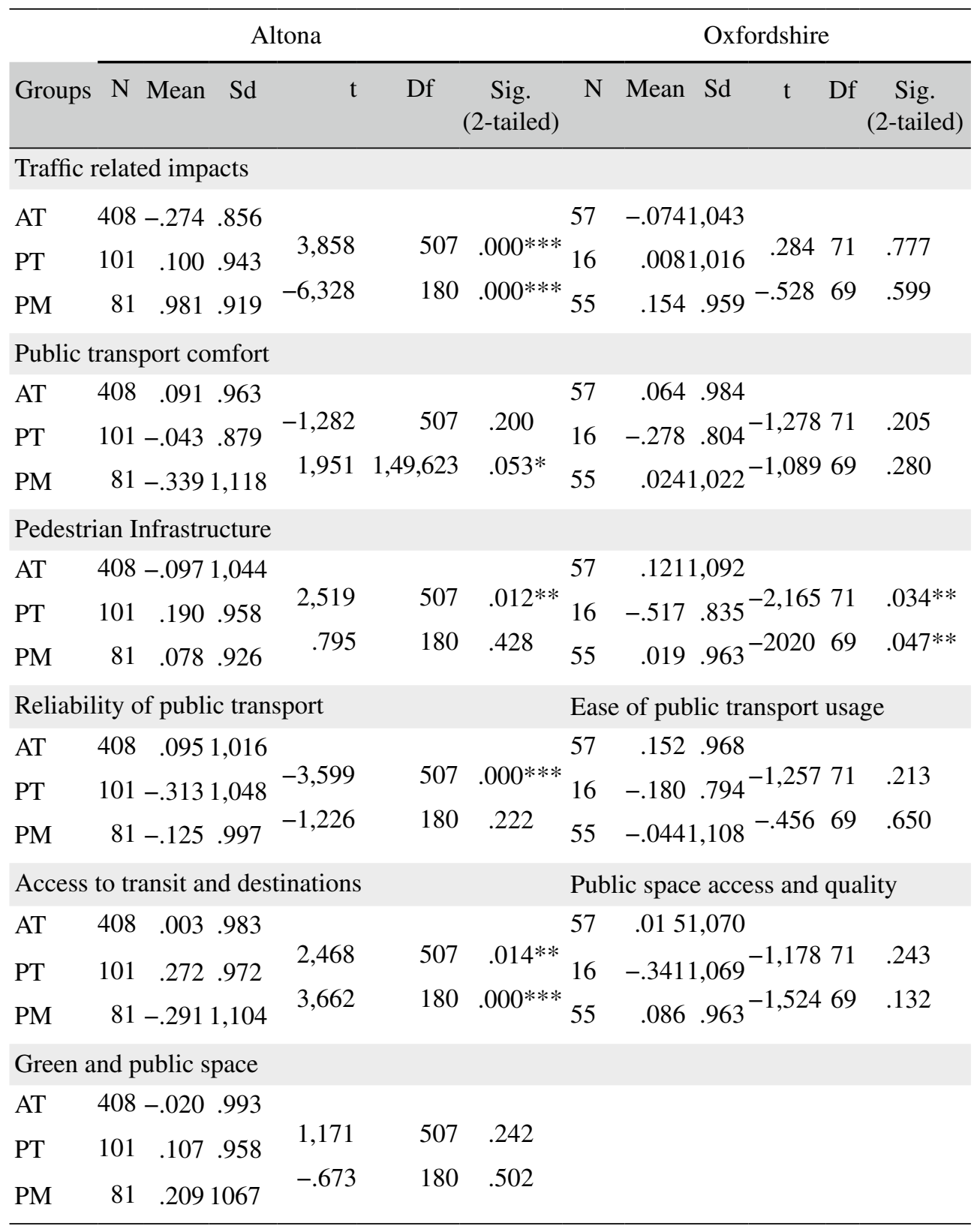

